\title{
Suppression of Co-intercalation on the Carbon Anode by MA Addition in a PC-base Electrolyte
}

\author{
Woo-Seong Kim, Dong-Won Park, Hwan-Jung Jung, and Yong-Kook Choi \\ ${ }^{\natural}$ RdD Center, DAEJUNG Chemicals \& Metals Co., Ltd., Gyeonggi-do 429-848, Korea \\ Department of Chemistry \& IBS \& RRC/HECS, Chomam National University, Gwangiu 500-757, Korea \\ "E-mail: vkchoi@chonnamackr. \\ Received Mav 11, 2005
}

\begin{abstract}
Propylene Carbonate (PC) has the interesting properties of being able to dissolve and dissociate lithium salts, thus leading to highly conducting electrolytes even at low temperatures. Moreover, electrolytes that contain PC are stable against oxidation at voltages up to $\sim 5 \mathrm{~V}$. Ilowever, it is known that, when lithium is intercalated into graphite in pure PC based electrolytes, solvent co-intercalation occurs, leading to the destruction of the graphite structure. (i.e. exfoliation). The objective of this study was to suppress PC decomposition and prevent exfoliation of the graphite anode by co-intercalation. Electrochemical characteristics were studied using Kawasaki mesophase fine carbon (KMFC) in different $1 \mathrm{M} \mathrm{LiPF}_{6} / \mathrm{PC}$-based electrolytes. Electrochemical experiments were completed using chronopotentiometry, cyclic voltammetry, impedance spectroscopy, X-ray diffraction, and scanning electron microscopy. From the observed results, we conclude that the $\mathrm{MA}$ and $\mathrm{Li}_{2} \mathrm{CO}_{3}$ additive suppressed co-intercalation of the $\mathrm{PC}$ electrolyte into the graphite anode. The use of additives, for reducing the extent of solvent decomposition before exfoliation of the graphite anode, could therefore enhance the stability of a $\mathrm{KMFC}$ electrode.
\end{abstract}

Key Words : Lithium ion battery, Co-intercalation, Propylene carbonate, Methyl acetate, Lithium carbonate

\section{Introduction}

Lithium ion batteries are generally composed of a lithiumcontaining transition metal oxide as the cathode material and graphite as the anode. Graphite represents a promising altemative anode material for replacing lithium metal, for use in rechargeable lithium ion batteries for overcoming safety problems and the short cycle of secondary lithium metal batteries. It has been reported that the charge process involves the intercalation of lithium between the graphene layers. Graphite undergoes a small volume change upon intercalation/de-intercalation and exhibits a high specific capacity, a highly desirable charge potential profile, and superior cycling behavior. However, irreversible reactions that take place with lithium during the first cycle represent one of the very persistent problems associated with the use of graphite as an anode material. On the surface of the graphite electrode, solvents are decomposed during initial intercalation process. Solvent decomposition is not simply co-intercalation. In particular, the graphite structure is destroyed due to solvent co-intercalation when solvent decomposition occurs on a graphite electrode surface.

Propylene carbonate (PC) has some interesting properties, one of which is its ability to dissolve and dissociate lithium salts leading to highly conducting electrolytes, even at low temperatures. Moreover, electrolytes containing PC as a unique solvent are stable against oxidation to voltages $\sim 5 \mathrm{~V}$ ' However, it is known that when lithium is intercalated into graphite in pure PC based electrolytes, solvent co-intercalation leads to the destruction of the graphite structure. (i.e., exfoliation) ${ }^{2-9}$ A number of attempts to suppress PC decomposition has been reported. Shu $e t$ al. proposed a method using a crown ether. ${ }^{10}$ Aurbach et al. reported on the effective influence of carbon dioxide. ${ }^{5}$ Najl et al. showed the effects of the addition of small amounts of halogenated like $\mathrm{Cl}-\mathrm{EC}, \mathrm{Br}-\mathrm{BL}$ or $\mathrm{Me}-\mathrm{CIF}$ to $\mathrm{PC} .{ }^{\prime \prime}$ In the absence of any additives, no reports have appeared on the stable performance of graphitized carbon. In this work, we attempted to suppress solvent decomposition and solvent co-intercalation in PC-base electrolyte by the use of $\mathrm{MA}$ and $\mathrm{Li}_{2} \mathrm{CO}_{3}$ as additives. Chronopotentiometry, cyclic voltammetry, impedance spectroscopy and conductivity meter were used to investigate the effect of additives ( $\mathrm{MA}, \mathrm{Li}_{2} \mathrm{CO}_{3}$ ). Scanning electron microscopy (SEM), X-ray diffraction (XRD) were also used to monitor changes in the surface morphology and structure due to the formation of a passivation film caused by solvent decomposition and the precipitation of $\mathrm{Li}_{2} \mathrm{CO}_{3}$ which was added to the electrolyte.

\section{Experimental Section}

A Kawasaki mesophase fine carbon (KMFC) electrode were prepared by mixing KMFC powder (Kawasaki Co. Ltd.) with polyvinyldifluoride (PVDF) as a binder, followed by pressing onto a copper foil using a stainless steel roller. After vacuum drying at $120^{\circ} \mathrm{C}$ for $6 \mathrm{hrs}$, the electrode was placed in a three-electrode cell. Lithium metal was used as the counter and reference electrodes. The reference electrode was sandwiched between a square KMFC electrode $\left(1 \mathrm{~cm}^{2}\right)$ and the $\mathrm{Li}$ counter electrode was separated with a glassy separator. This procedure was carried out under an atmosphere of argon. The electrochemical properties of solvent 
decomposition on the KMFC slectrode were investigated using an organic electrolyte system. High-purily propylene carbonate ( $\mathrm{PC}, \Lambda \mathrm{ddrich}$ ) and Methyl acetate (MA, Nldrich) were used as solvents for the electrolyte solution. Lithium hexafluoro phosphate, LiPF, (Aldrich) was used as the electrolytic salt. All solvents, electrolytic salts, and the prepared electrolyte were stored in a glowe box purged by $\mathrm{Ar}$ gas. Lithium carbonate, $\mathrm{Li}_{2} \mathrm{CO}_{3}$ ( $(\mathrm{Alodrich}$ ), was added to the prepared electrolyte. In fact, $\mathrm{Li}_{2} \mathrm{CO}_{3}$ was found to dissolve with difliculty in the organic solvent and it was necessary to stir the solution for a week to obtain an electrolytic solution. Finally, however, an electrolyte that was saturated with $\mathrm{Li}_{3} \mathrm{CO}_{3}$ was oblained.

Chronopotentiometry and cyclic voltammetry were used to study the initial irreversible reactions and solvent decomposition. The properties of the passivation fim on the $\mathrm{KMFC}$ and the lirst intercalation of $\mathrm{Li}$ in $\mathrm{KMFC}$ throngh the passivation film were investigated by a.c. impedance spectroscopy by means of a Potentiostat/Galvanostat (F:G\&G model 273A) and Lock-in Amplifier (FG\&G model 5210). An impedance measurement was perfomed by applying the previously measured open-circuil potential, overlaid with a $5 \mathrm{mV}$ harmonic perturbation signal in the frequency range from $100 \mathrm{kJl}$. $1010 \mathrm{~mL}$ 7. These measurements were carried out at room temperature. An SFM analysis of the samples involved the use of a JSM- 5400 Scanning Microscope (NORAN Instruments). The working voltage was set at $20 \mathrm{kV}$ and the working distanee of the lens was set at $27 \mathrm{md}$. After charging the KMFC elcetrode to 0.0 $\mathrm{V}$ (vs. $\mathrm{Li} / \mathrm{Li}$ ) and discharging it to $2.0 \mathrm{~V}(\mathrm{vs}$. $\mathrm{Li} / \mathrm{Li}$ ), the sample was rinsed with $M A$ to remove the electrolyle and dried in a vacuum. XRD measurements (Rigaku D/max1200) were used to investigate the structure of the Solid Flectrolyte Interphase (SFA) film. These measurements were carried oul at room temperature.

\section{Results and Discussion}

Figure 1 shows the initial charge curve for the KMFC electrode in $1 \mathrm{M} \mathrm{LiPF} /$ pure $\mathrm{PC}$ and $1 \mathrm{M} \mathrm{LiPF}_{6} / \mathrm{PC}:$ DFC (4 $: 1$, wolume ratio) at a low rate of $0.5 \mathrm{~m} / / \mathrm{cm}^{2}$. The voltage on the initial charge decreased very rapidly from the open circuit voltage (OCV) to $0.9 \mathrm{~V}$ ( voltage plateaus were observed at around $0.8 \mathrm{~V}$ (vs. Li// $\mathrm{Li}$ ), as the result of decomposition of the PC electrolyte, as has been reported previously. ${ }^{32-3 x}$ When lithium in a PC electrolyte is intercalated into the KMFC electrode, solvent cointercalation and subsequent destruction of the KMFC electrode structure and exfoliation of the graphene layers occurs due to both continuous PC decomposition without stable passivation film formation and continuous PC-Li cointercalation into the graphene layers. PC decomposition on KMFC clectrode is also accompanied by large amounts of gas cvolution, which was assumed to be propylene gas. Fxfoliation may be enhanced in cases where the reduction of the solvaled molecules leads to the production of gas. $\mathrm{As}$ the result, in the PC electrolyte, the KMFC electrode did not

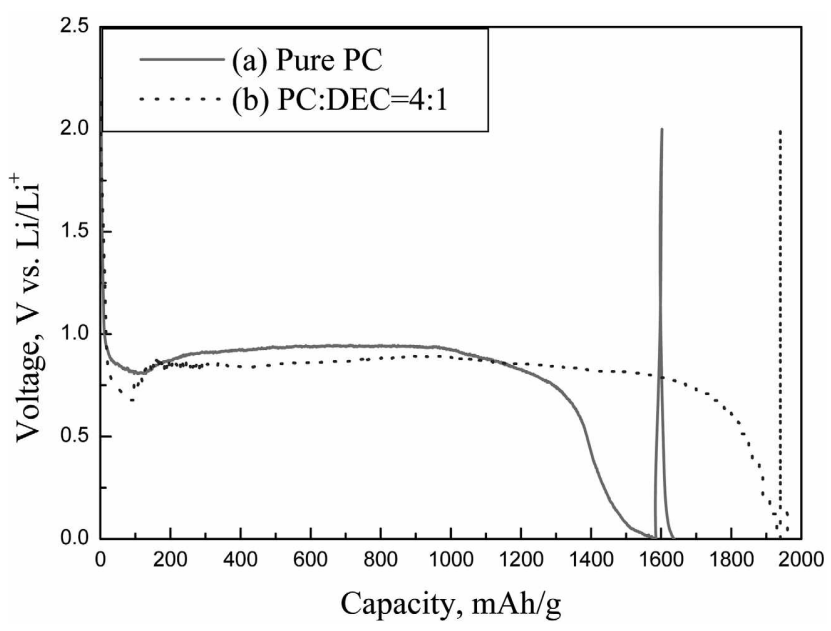

Figure 1. Vollage-capacity proliles ol the KMFC electrode in (a) I

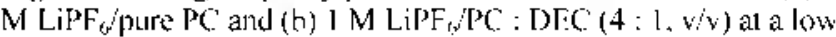
ralc of $0.5 \mathrm{~m} / \mathrm{\textrm {cm } ^ { 2 }}{ }^{2}$.

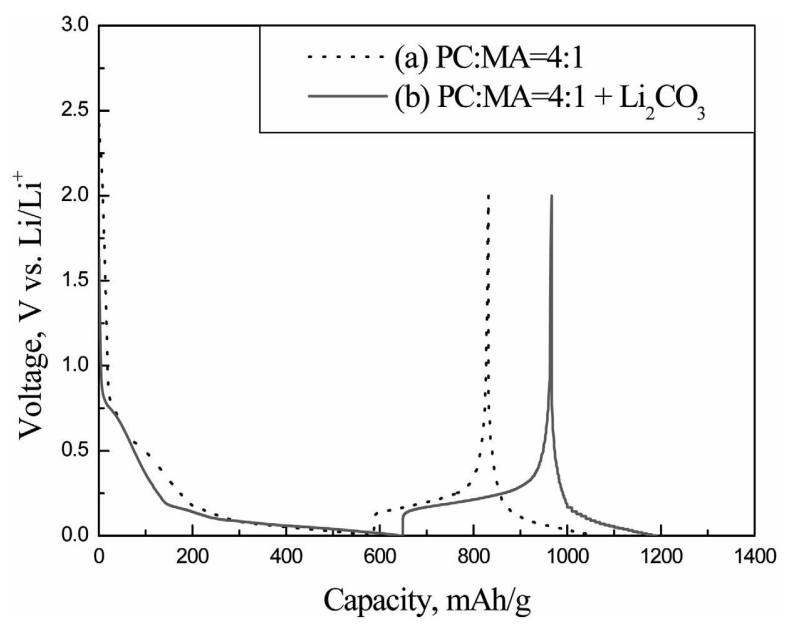

Figure 2. Voltage-capacity proliles of the KMFC electrode in (a) I $\mathrm{M} \mathrm{LiI} \mathrm{F}_{6} / \mathrm{PC}: \mathrm{M} \Lambda(4: 1, v / v)$ and (b) $1 \mathrm{M} \mathrm{LiPF}_{6} / \mathrm{I}^{2} \mathrm{C}: \mathrm{M} /(4: 1$, $\sqrt{ } / \mathrm{v})$ । L.in $\mathrm{CO}_{3}$ al a low rate of $0.5 \mathrm{~m} \Lambda / \mathrm{cm}^{2}$.

undergo intercalation and exfoliation occurred by solvent decomposition with gas evolution. The initial charge curve for an KMFC electrode in I M LiPF, /PC : DEC $(4: 1, v / v)$ was similar in behavior to that when PC was used as a singlo solvent.

Figure 2 shows voltage-capacity proliles of an KMFC electrode in $1 \mathrm{M} \mathrm{LiPF}_{6} / \mathrm{PC}: \mathrm{M} \wedge(4: 1, \mathrm{v} / \mathrm{v})$ and $1 \mathrm{M} \mathrm{LiPF}_{6}$ $\mathrm{PC}: \mathrm{MA}(4: 1, \mathrm{v} / \mathrm{v})+\mathrm{Li}_{2} \mathrm{CO}_{3}$ at a low rate of $0.5 \mathrm{~m} \Lambda / \mathrm{cm}^{2}$. The voltage plateau by $\mathrm{PC}$ decomposition at $0.8 \mathrm{~V}$ (ves. Li/ $\mathrm{Li}$ ) was eflectively suppressed when an electrolyte containing the $M \Lambda$ electrolyte was used as a co-solvent. This provides clear evidenee that the $\mathrm{M} \wedge$ clectrolyte suppresses PC decomposition on the KMFC electrode surface. This suggests that a stable passivation film is formed in an electrolyte containing $\mathrm{PC}$ by the $\mathrm{MA}$ electrolyte of the decomposition products on the KMFC electrode. Accordingly, a stable passivating layer is formed during the initial intercalation in a half-cell using the MA electrolyle as a cosolvent of the PC electrolyte, which covers the K.MFC 

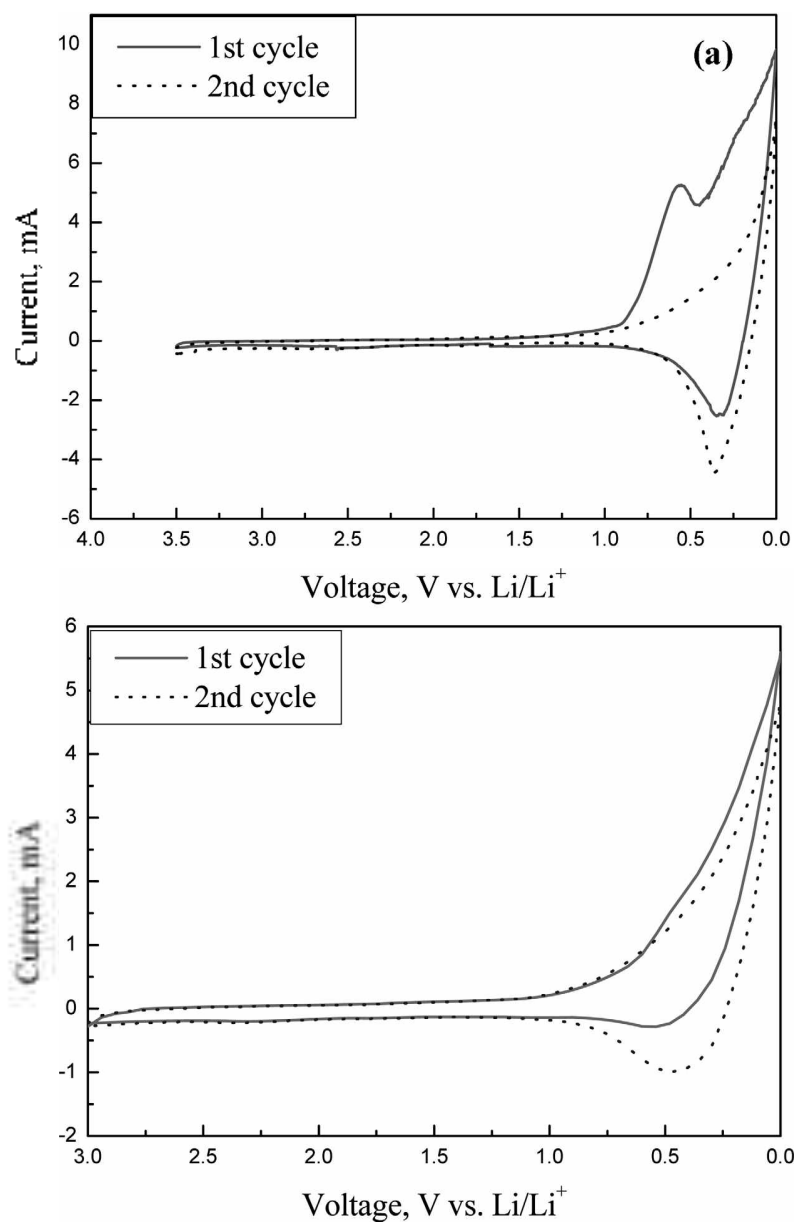

Figure 3. Cyclic vollammograms of the KMFC dectrode in (a) 1 $\mathrm{M} \mathrm{LiPF} / \mathrm{PC}: \mathrm{M \Lambda}(4: 1$, v/v) and (b) $1 \mathrm{M} \mathrm{LiPF} / \mathrm{PC}: \mathrm{MA}(4: \mathrm{l}$, $v / v)+\mathrm{Li}_{2} \mathrm{CO}_{3}$

electrode. The film acts as a sereen that filters out solvated molecules of the PC electrolyte allowing only the migration of $\mathrm{Li}^{\prime}$ into the KMFC layers. Consecuently, the passivation film formed by MA decomposition prevents the co-intercalation of the $\mathrm{PC}$ electrolyte and exfoliation of the KMFC electrode. The decomposition of the PC electrolyte on the KMFC electrode in an electrolyte with $\mathrm{I}_{2} \mathrm{CO}_{3}$ is suppressed to a greater extent than that of the electrolyte without $\mathrm{Li}_{2} \mathrm{CO}_{3}$. These results can be atributed to the passivation film formed by adding $\mathrm{Li}_{2} \mathrm{CO}_{3}$ in the electrolyte having improved properties.

The suppression of solvent decomposition by the addition of $\mathrm{MA}$ and $\mathrm{L}_{2} \mathrm{CO}_{3}$ can be clearly seen in cyclic voltammograms, as shown in Figure 3. The latter figure is a comparison of cyclic voltammograms of a KMFC electrode in $1 \mathrm{M}$ $\mathrm{LiPF}_{6} / \mathrm{PC}: \mathrm{MA}(4: \mathrm{I}, \mathrm{v} / \mathrm{v})$ and $1 \mathrm{M} \mathrm{LiPF} / \mathrm{PC}: \mathrm{M} \Lambda$ (4: I, $\mathrm{v} / \mathrm{v})$ containing $\mathrm{Li}_{2} \mathrm{CO}_{3}$.

In the case of $1 \mathrm{M} \mathrm{LiPF} / \mathrm{PC}: \mathrm{M} /(4: 1, \mathrm{v} / \mathrm{y})$, the reduction peaks caused by $\mathrm{PC}$ deconposition have nearly disappeared. It is clear that $P C$ decomposition at $0.8 \mathrm{~V}$ ( $15 . \mathrm{Li} / \mathrm{Li}$ ) was suppressed when $\mathrm{MA}$ was used as a co-solvent. It would appear that the $\mathrm{MA}$ decomposition products were deposited on the KMFC electrode surlace before reaching the voltage (a)

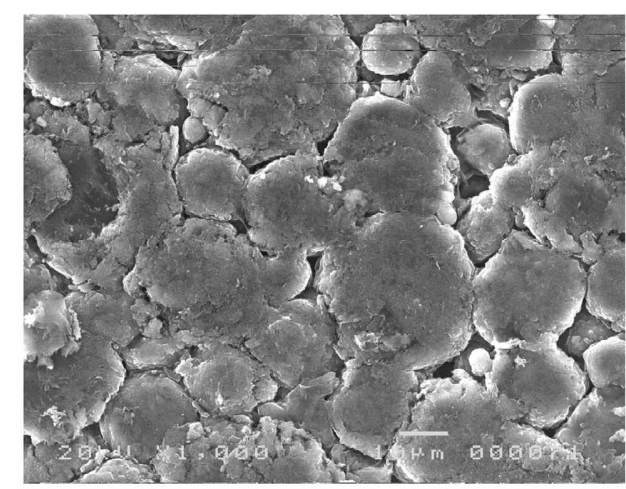

(b)

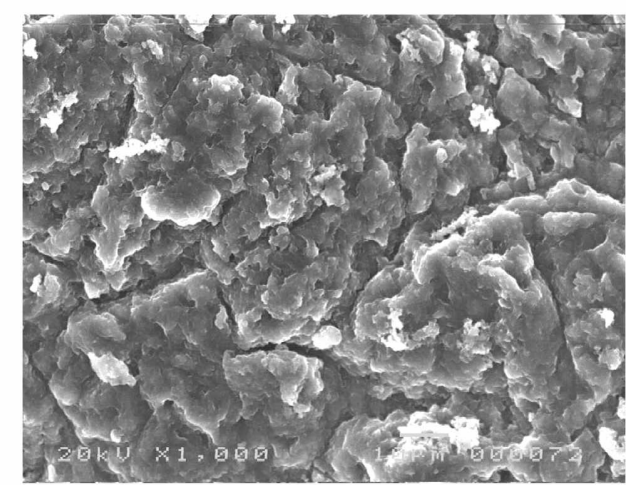

(c)

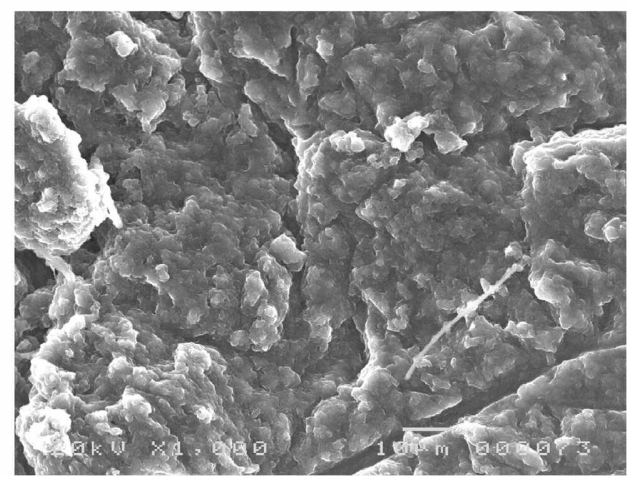

Figure 4. SEM images of the KMFC elcetrode surface in (a) bare,

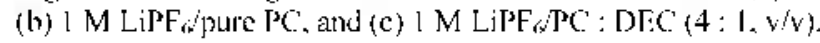

for PC decomposition, and, as a result, the electrolyte using $\mathrm{MA}$ as a co-solyent did not cause exfoliation. This indicales that the PC solvent did not melt the passivation film formed by the decomposition of MA. Therefore, the passivation film formed by the decomposition of $\mathrm{MA}$ inhibited $\mathrm{PC}$ decomposition and co-intercalation on the KMFC electrode. No peaks corresponding to solvent decomposition appeared in a second scan, which is consistent with the SEM images. The suppression of solvent decomposition by the added $\mathrm{Li}_{2} \mathrm{CO}_{3}$ can be clearly seen in the cyclic voltammograns shown in Figure 3(b). In the case of the electrolyte added $\mathrm{L}_{2} \mathrm{CO}_{31}$ reduction peaks caused by the decomposition of $\mathrm{PC}$ are strongly stippressed and the cathodic peak of MA at approximately $0.6 \mathrm{~V}$ ( $v$ s. $\mathrm{L}, \mathrm{i} / \mathrm{Li}$ ) has disappcared. This suggests that the passivation film formed by electrolyte added $\mathrm{Li}_{2} \mathrm{CO}_{3}$ was superior to that in which MA was used as a co-solven.

To confirm the above results, the surface morphologies of the KMFC electrode were observed by scanning electron 
microscopy (SFM). The original KMFC electrode surface was initially measured in order to compare it with the initial intercalated electrode surface. The original KMFC electrode surface, in which carbon beads are distributed, is shown in Figure 4(a). The diameter of the KMFC electrode was not regular for particle sizes of less than $20 \mu \mathrm{m}$. Alter the inlerealation of $\mathrm{Li}$ into the KMFC clectrode in the I M $\mathrm{LiPF}_{6}$ /pure PC electrolyte, the deposited KMFC electrode surface was investigated and this result is shown in Figure 4(b). The surface of the intercalated KMFC electrode has a clearly different surface morphology from the original electrode surface. The morphology of the KMFC electrode after the $1^{x t}$ intercalation in the PC electrolyte was changed, compared to the original KMFC electrode. These morphological changes can be attributed to exfoliation of the KMFC electrode by continuous PC decomposition. Therefore, KMFC electrode rapidly undergoes exfoliation when it is charged in $1 \mathrm{M} \mathrm{LiPF}$ /pure PC. $\mathrm{As}$ can be seen in Figure 4(c), the KMFC electrode was also destroyed in I M LiPF PC : D) :C $(4: 1, v / v)$.

Figure 5(a) and 5(b) shows the lithiated KMFC electrode in $1 \mathrm{M} \mathrm{LiPF}_{6} / \mathrm{PC}: \mathrm{M} \Lambda(4: 1, \mathrm{v} / \mathrm{v})$ and $1 \mathrm{M} \mathrm{L}, \mathrm{PPF}_{6} / \mathrm{PC}: \mathrm{MA}$ $(4: 1, \mathrm{v} / \mathrm{v}) \div \mathrm{Li}_{2} \mathrm{CO}_{3}$. As shown Figure $5(\mathrm{a})$ and $5(\mathrm{~b})$, both the morphology of the KMFC electrode in $1 \mathrm{M} \mathrm{LiPF}_{6} / \mathrm{PC}$ : $\mathrm{M} \wedge(4: 1, v / v)$ and $1 \mathrm{ML} \mathrm{LPF}_{6} / \mathrm{PC}: \mathrm{M} \wedge(4: 1, v / \mathrm{v})+\mathrm{Lij}_{2} \mathrm{CO}_{3}$ did not undergo exfoliation, as in $1 \mathrm{M} \mathrm{LiPF}_{6} / \mathrm{pure}^{\mathrm{PC}}$. These results indicate that the stable passivation film formed by $\mathrm{M} \wedge$ as a co-solvent of the PC electrolyte prevented the cointercalation of solvent into the graphene layers which resulted in exfoliation of the KMFC electrode. The more compact passivation lilm formed by the electrolyte added

(a)

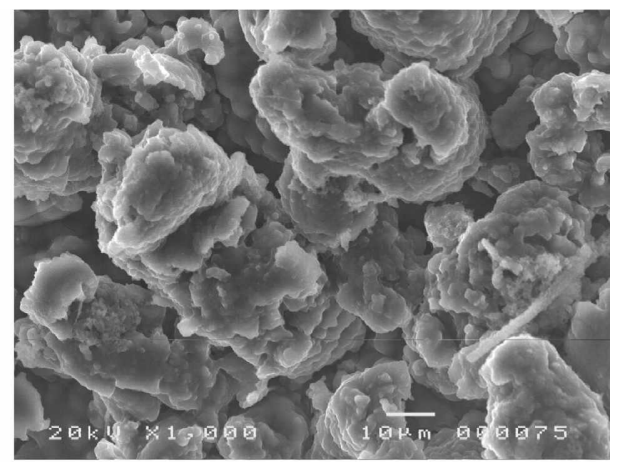

(b)

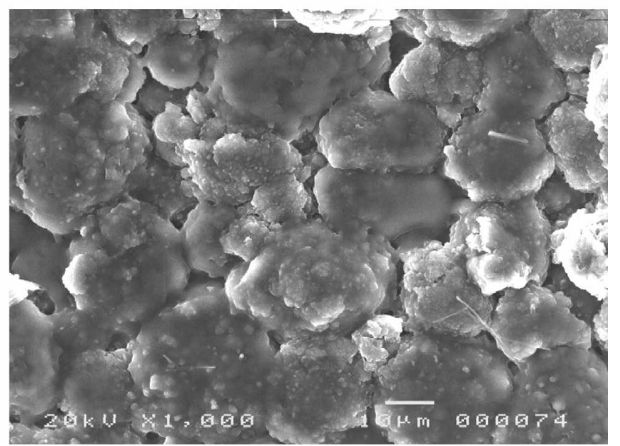

Figure 5. S5M images of the KMFC electrode surface in (a) I M I.PPF, $P C: M \wedge(4: 1, v / v)$, and (b) I $M I . i P F / P C: M \wedge(4: 1, v / v)$ $\mathrm{I}_{\mathrm{i}} \mathrm{COO}_{3}$.

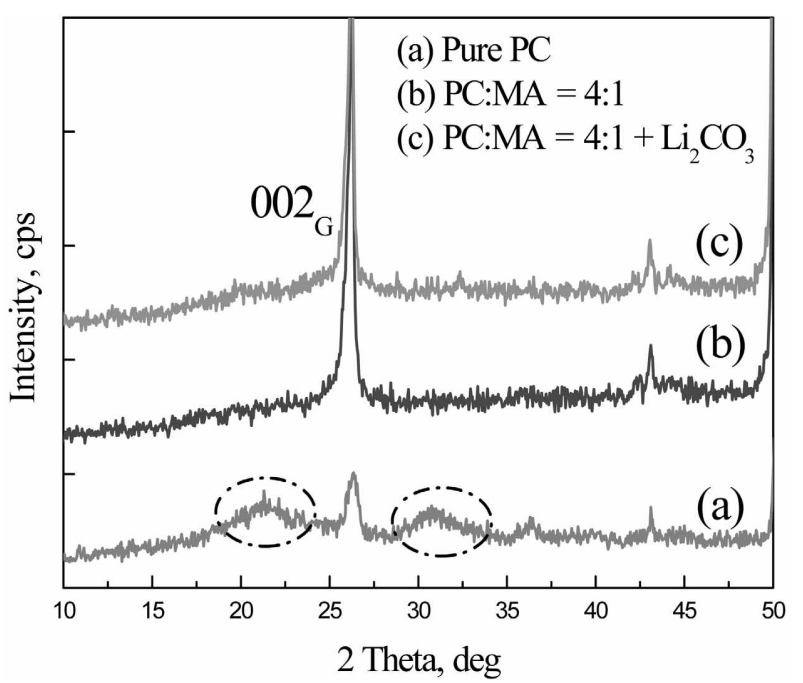

Figure 6. XRI) pattens of (he KMFC alectrode after intercalation in (a) I M LiPF, pure PC. (b) I M LiPF $/ \mathrm{PC}: \mathrm{MA}(4: 1$, v/v), and (c) I $\mathrm{MLiP \Gamma} / \mathrm{PC}: \mathrm{MA}(4:$ I. $/ / \mathrm{v})+\mathrm{Li}_{2} \mathrm{CO}_{3}$.

$\mathrm{Li}_{2} \mathrm{CO}_{3}$ as an additive has exeellent properties and results in a fine deposil of encapsulated KMFC beads. The lilm was dense and no dissolution of the PC electrolyte was evident. These results were also consistent with voltage-capacity proliles and XRD data.

To investigate the structure of the SEI formed by solvent decomposition, an XRD analysis was performed after the $1^{\text {st }}$ charge in these electrolyles. These results are shown in Figure 6. Several (002) peaks corresponding to graphite carbon were detected al about $26^{\circ}$. However, the XRI) pattern of the KMFC electrode in the pure PC electrolyte was elearly different from that for the electrolyte to which $\mathrm{M} \wedge$ and $\mathrm{Li}_{2} \mathrm{CO}_{3}$ were added. In the pure $\mathrm{PC}$ electrolyte, the broad region is indicative of an anorphous phase and is believed to be due to structural changes by PC decomposition. $\Lambda \mathrm{s}$ a result, we conclude that $\mathrm{M} \Lambda$ and $\mathrm{Li}_{2} \mathrm{CO}_{3}$, when added to the electrolyte, prevented co-intercalation by $\mathrm{PC}$ decomposition, thus preventing the destruction of the KMFC electrode structure.

Figure 7 shows inpedance spectra measured al various potentials during the initial charge process. This ligure is a comparison of the impedance spectra of a KMFC electrode in $1 \mathrm{M} \mathrm{LiPF} /$ pure $^{\mathrm{PC}}, 1 \mathrm{M} \mathrm{LiPF}_{6} / \mathrm{PC}: \mathrm{M} \wedge(4: 1, \mathrm{v} / \mathrm{v})$ and 1 M LiPF $/ \mathrm{PC}: \mathrm{MA}(4: 1, \mathrm{v} / \mathrm{v})$ containing $\mathrm{Li}_{2} \mathrm{CO}_{3}$. The measured potential is $3.0,2.0,1.5,1.0,0.8,0.5,0.4,0.3,0.2,0.1$ and $0.0 \mathrm{~V}(\mathrm{ws} . \mathrm{L}, \mathrm{L} / \mathrm{Li}$ ) in the frequency range from $64 \mathrm{kII} \%$ to $0.01 \mathrm{Jz}$. The interpretation of the impedance spectra is based on a simple equivalent circuit model proposed by Takani et al. ${ }^{14}$ The diarrams (Figure 7) show two semicircles on a complex plane. The semicircle in the high frequency region corresponds to the SFI film and those in a low frequency are derived from charge transfer between the electrolyte and the electrode interface. Film resistance was unifom in the high frepuency range for the case of the SEI film formed by I $\mathrm{M} \mathrm{LiPF}, 6 \mathrm{PC}: \mathrm{M} \wedge(4: 1, \mathrm{v} / \mathrm{v})$ and $\mathrm{I} \mathrm{M}$ $\mathrm{LiPF}_{6} / \mathrm{PC}: \mathrm{M} \wedge(4: 1, \mathrm{v} / \mathrm{v}) \div \mathrm{Li}_{2} \mathrm{CO}_{3}$. The film resistance, as 
(a)

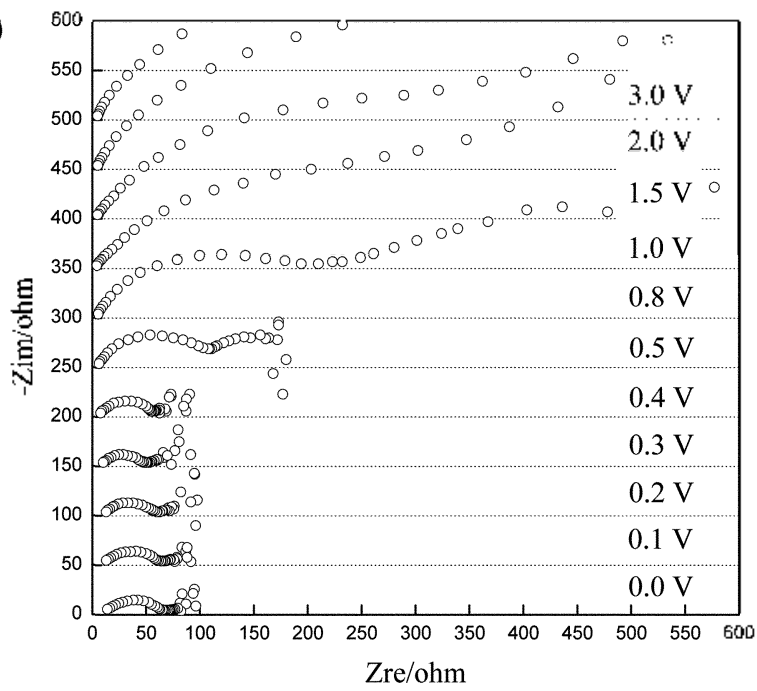

(b)

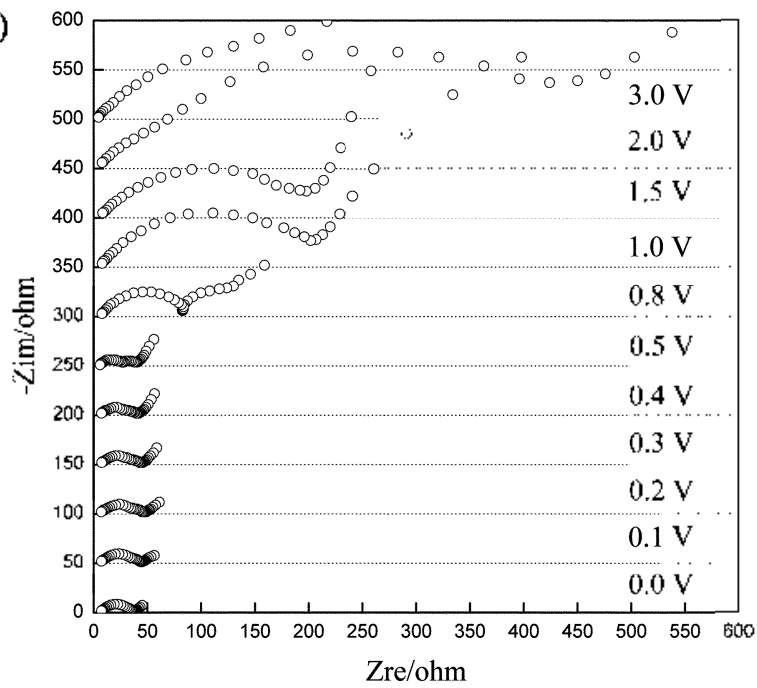

(c)

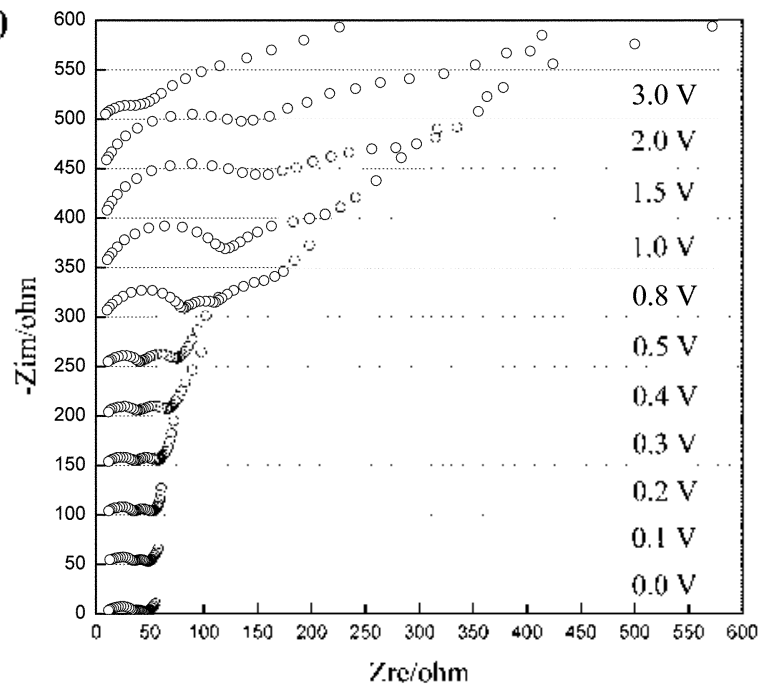

Figure 7. Impedance spectra of the KMFC electrode in (a) $1 \mathrm{M}$ $\mathrm{LiPF}_{t}$ pure PC, (b) I M LiPF $d$ PC : MA (4: I, viv), and (c) $1 \mathrm{M}$ $\mathrm{LiPF}_{s i} \mathrm{PC}: \mathrm{MA}(4: 1, \mathrm{v} / \mathrm{v})+\mathrm{Li}_{2} \mathrm{CO}_{3}$.

the result of $1 \mathrm{M} \mathrm{LiPF}_{6} / \mathrm{Pure} \mathrm{PC}$ was, however, changed in the high frequency region during the film formation process. Continuous PC decomposition did not allow the formation of compact surface films. Based on this result, the SEI film on the KMFC electrode in $1 \mathrm{M} \mathrm{LiPF}_{6} / \mathrm{PC}$ : MA $(4: 1, v / v)$ and $1 \mathrm{M} \mathrm{I.PF}_{6} / \mathrm{PC}$ : $\mathrm{MA}(4: 1, \mathrm{v} / \mathrm{v})$ containing $\mathrm{Li}_{2} \mathrm{CO}_{3}$ appears to be very stable, compared to an electrolyte containing only $\mathrm{PC}$.

\section{Conclusions}

Methyl acetate (MA) and lithium carbonate $\left(\mathrm{L}_{2} \mathrm{CO}_{3}\right)$ were added to a propylene carbonate ( $\mathrm{PC}$ ) containing electrolyte in order to prevent the co-interealation of PC. It was revealed by voltage-capacity profiles, STM images, and XRD data that the addition of MA and $\mathrm{I}_{2} \mathrm{CO}_{3}$ suppressed the exfoliation of KMFC electrode caused by a continuous PC decomposition. The a.c. impedanee spectra showed that the passivation film in the MA and $\mathrm{Li}_{2} \mathrm{CO}_{3}$ containing $\mathrm{PC}$. electrolyte had lower resistance than that formed in the PC only electrolyte. In comparison with the porous passivation film in a pure $\mathrm{PC}$ electrolyte, the electrolyte containing MA as a co-solvent and $\mathrm{Li}_{2} \mathrm{CO}_{3}$ as an additive exhibited two advantages of suppressing the decomposition of $\mathrm{PC}$ and forming a stable SET film with low resistance.

Acknowledgments. This study was financially supported by Special research fund of Chonnam National University in 2004.

\section{References}

I. Arakawa, M.; Yamaki, I.-]. J. Power Sontres 1995, 54, 250.

2. Shu, Z. X.; McMillan. R. S.; Muray, J. J. .J. Electrochem. Soc. 1995, $140,2873$.

3. Dey, A. N.: Sullivan, B. P. J. Electrochem. Soc, 1970, 117. 222.

4. Fong, R.; Van Sacken, U.; Dahn, J. R. J. Electrechem. Soc: 1990, 137,2009

5. Aurbach, D.; Ein-Eli, Y.: Chusid, O. Y.: Carmeli, Y.; Babai, M.; Yamin. I1. J. Electrochem. Soc. 1994, /4/, 603.

6. Aurbach, D.; Chusid, O. Y.; Carmeli, Y.: Babai, M.; Ein-Eli, Y. J. Ponver Sources 1993, 43, 47.

7. Aurbach, D.; Ein-Eli, Y.; Markovsky, B.; Carmeli, Y.; Yamin, H.; I.uski, S. Ffectrochimi. Acto 1994. 39, 2559.

8. Dalun. J. R.; Fong, R.; Spoon, M. J. Phe Rev: B 1990, 42, 6424.

9. Abe. T.; Kawabata. N.; Mizulani, Y.; Inaba, M.: Ogumi, Z. J. Electroctiom. Soc. 2003, 150, A257.

10. Shu, Z. X.; McMillan, R. S; Murray, J. J. J. Electrochen. Soc. 1993. 140,922 .

11. Naji, A.; Gihanbaja, J:; Willmann, P.; Billaud. D. Ffectrochint. Actc 2000, 45, 1893.

12. Zliang, X.; Koslecki, R.; Richard Son, T. J.; Pugh, J. K.; Ross, Jr, P. N. J. Electrochen. Soc: 2001. 148, A 13141

13. Chung, G. C.; Kim, H. J.; Yu, S. I.; Jun, S. H.; Choi, J. W.; Kin, M. H. J. Electrochem. Soc: 2000, $147,4391$.

14. Wang, C.; Appleby. A. I.; I.ittle, Г. F. J. Electroanol Chem. 2002. 519,9 .

15. Billaud, D.: Naji. A.; Willmamn, P. .. Chem Soc., Chem Commen. 1995,1867 .

16. Ding, M. S.; Jow, T. R. J. Electrochem. Soc. 2003, 150, A620.

17. Pan, Q.; Guo, K; Wang, L.; Fang, S. J. Electruchem. Soc: 2002, 149. $\wedge 1218$.

I8. Zloang, S. S.; Xu, K.; Allen, J. L.; Jow, T. R. J. Power Somces $2002,110,216$

19. Iakami, N.; Satoch. A.; Hara, M.; Ohsaki, T. J. Electrochem. Soc: 1995, 142,371 . 